\title{
Langerhans Cell Histiocytosis with Isolated Central Diabetes Insipidus, Low Grade Fever and Sellar Erosion
}

\author{
İclal Okur ${ }^{1 \oplus}$, Hasan Arı $^{1 \oplus}$, Semra Çetinkaya ${ }^{1 \oplus}$, Betül Emine Derinkuyu ${ }^{2 \oplus}$, Gizem Çağlar ${ }^{3} \oplus$ \\ Hasibe Gökçe Çınar ${ }^{2} \oplus$, Şule Yeşil ${ }^{4}$, Şenay Savaş Erdeve ${ }^{1 \oplus}$
}

\begin{abstract}
1 University of Health Sciences Turkey, Dr. Sami Ulus Obstetrics And Gynecology, Children's Health and Disease Training and Research Hospital, Department of Pediatric Endocrinology, Ankara, Turkey

2 University of Health Sciences Turkey, Dr. Sami Ulus Obstetrics and Gynecology, Children's Health and Disease Training And Research Hospital, Department of Pediatric Radiology, Ankara, Turkey

${ }^{3}$ University of Health Sciences Turkey, Dr. Sami Ulus Obstetrics and Gynecology, Children's Health and Disease Training and Research Hospital, Department of Pediatrics, Ankara, Turkey

${ }^{4}$ University of Health Sciences Turkey, Dr. Sami Ulus Obstetrics and Gynecology, Children's Health and Disease Training and Research Hospital, Department of Pediatric Oncology, Ankara, Turkey
\end{abstract}

Cite as: Okur I, Arı H, Çetinkaya S, Derinkuyu BE, Çağlar G, Çınar HG, Yeşil S, Erdeve SSS. Langerhans cell histiocytosis with isolated central diabetes Insipidus, low grade fever and sellar erosion. Trends in Pediatrics 2021;2(2):104-8.

Received: 12 January 2021

Accepted: 26 February 2021

Publication date: 29 June 2021

Keywords: Bone lesion, central diabetes insipidus, children, Langerhans cell histiocytosis, sellar erosion

İclal Okur

University of Health Sciences Turkey, Dr. Sami Ulus Obstetrics and Gynecology, Children's Health and Disease Training and Research Hospital, Department of Pediatric Endocrinology, Ankara, Turkey ORCID: 0000-0002-7944-3351

iclalokur@yahoo.com

H. Arı 0000-0002-7716-6661

S. Çetinkaya 0000-0003-3974-2872

B. E. Derinkuyu 0000-0003-2434-1398

G. Çağlar 0000-0002-5676-1461

H. G. Cinar 0000-0003-2687-1544

Ş. Yeşil 0000-0002-2328-8612

S. S. Erdeve 0000-0002-4164-5089

\author{
ABSTRACT
}

Langerhans cell histiocytosis ( $L C H)$ is a rare disease of the monocyte-macrophage system. Although it is known that bone involvement is seen very frequently in cases with $\mathrm{LCH}$, our case is the first case with a lytic-destructive lesion in the bone structure forming sella turcica.

A 4-year-old, 5-month-old male patient who applied to our outpatient clinic was diagnosed with Langerhans cell histiocytosis in further examination after the diagnosis of central diabetes insipidus (CDI) was made. On cranial magnetic resonance imaging (MRI), widespread lytic-destructive bone lesions were observed in the bone structure forming the sella (sphenoid bone), sellar destruction not previously described in the literature.

Sellar erosion has not been reported before in cases diagnosed with $\mathrm{LCH}$ in the literature. The presence of low-grade fever in a patient presenting with isolated $C D I$ is a warning sign for the diagnosis of $\mathrm{LCH}$. 


\section{INTRODUCTION}

Langerhans cell histiocytosis (LCH) is a rare clonal disease of the monocyte-macrophage system characterized by uncontrolled proliferation and accumulation of dendritic cells. ${ }^{1}$ Its annual incidence rate is estimated as 5 per million for children under the age of $15 .^{2}$

It is diagnosed with clinical and radiological findings together with histopathological analyzes and shows a wide range of clinical findings from self-healing lesions to life-threatening widespread involvement. ${ }^{1}$ Unifocal involvement $(57 \%)$ is the most common form in children diagnosed with $\mathrm{LCH}$, while multisystemic involvement (17\%) is less frequent.

Central nervous system involvement is seen in approximately $5 \%$ of patients with $\mathrm{LCH}$, and the hypothalamus-pituitary axis (HPA) is most frequently affected as a result of the destruction or degeneration of neurons in the supraoptic and paraventricular nuclei of the hypothalamus. ${ }^{3}$

Our case that was found to have central diabetes insipidus on admission to our clinic with the complaints of polyuria and polydipsia, was diagnosed with multisystem involvement $\mathrm{LCH}$ when evaluated with intermittent mild fever. We wanted to present our case so as to share our experiences during the diagnostic process.

\section{CASE REPORT}

A 4-year-5-month-old male patient was referred to our outpatient clinic with complaints of drinking too much water and urinating frequently for 2 months. It was learned that he drank 5-6 liters $\left(7-8 \mathrm{~L} / \mathrm{m}^{2}\right)$ of water per day. There was no history of vomiting or weight loss. He did not have a history of chronic disease, continuous medication use, head trauma, or previous infection. On physical examination, his height $(103.3 \mathrm{~cm}$ : standard deviation score (SDS): 0.89 ), body weight (17.8 kg; SDS: 0.07), body mass index $\left(16.7 \mathrm{~kg} / \mathrm{m}^{2} ;\right.$ SDS: 0.74$)$, testicular volüme $(2 / 2$ $\mathrm{ml})$, and stretched penile length $(4.2 \mathrm{~cm})$ were measured. His pubic hair growth was in stage- 1 and prepubertal. Other system examinations were normal except for dry skin. Remarkable laboratory test results were as follows: hemoglobin $(\mathrm{Hb}): 110$ $\mathrm{g} / \mathrm{L}$, white blood cell count $(\mathrm{WBC}): 10.8 \times 10^{9} / \mathrm{L}$, platelet (PLT): $602 \times 10^{9} / \mathrm{L}$, blood glucose: $4.3 \mathrm{mmol} / \mathrm{L}$, blood-urea-nitrogen: $2.1 \mathrm{mmol} / \mathrm{L}$, creatinine: 41.5 $\mu \mathrm{mol} / \mathrm{L}$, sodium: $141 \mathrm{mmol} / \mathrm{L}$, potassium: 4.65 $\mathrm{mmol} / \mathrm{L}$, aspartate aminotransferase: 27 units/L, alanine aminotransferase: 8 units/L, urine density: 1001, and urine $\mathrm{pH}: 6$. The patient was admitted to the pediatric endocrinology service for further examination and treatment with a pre-diagnosis of diabetes insipidus.

After water deprivation test, the patient was diagnosed with diabetes insipidus, and urinary osmolarity increased from $121 \mathrm{mOsm} / \mathrm{L}$ to 407.7 $\mathrm{mOsm} / \mathrm{L}$ after administration of 10 micrograms of desmopressin acetate nasal spray solution (Table 1). With these findings, the patient was diagnosed with central diabetes insipidus (CDI) and desmopressin treatment was initiated. The patient's symptoms of polyuria and polydipsia improved with 3 daily doses of 30 microgram desmopressin acetate (MINIRIN $^{\circledR}$ Melt).

The anterior pituitary functions of the patient were examined (Table 2). A borderline increase in prolactin level, low levels of insulin-like growth factor-1 (IGF-1), slightly lower thyroid-stimulating hormone with normal free thyroxine, adrenocorticotropic hormone

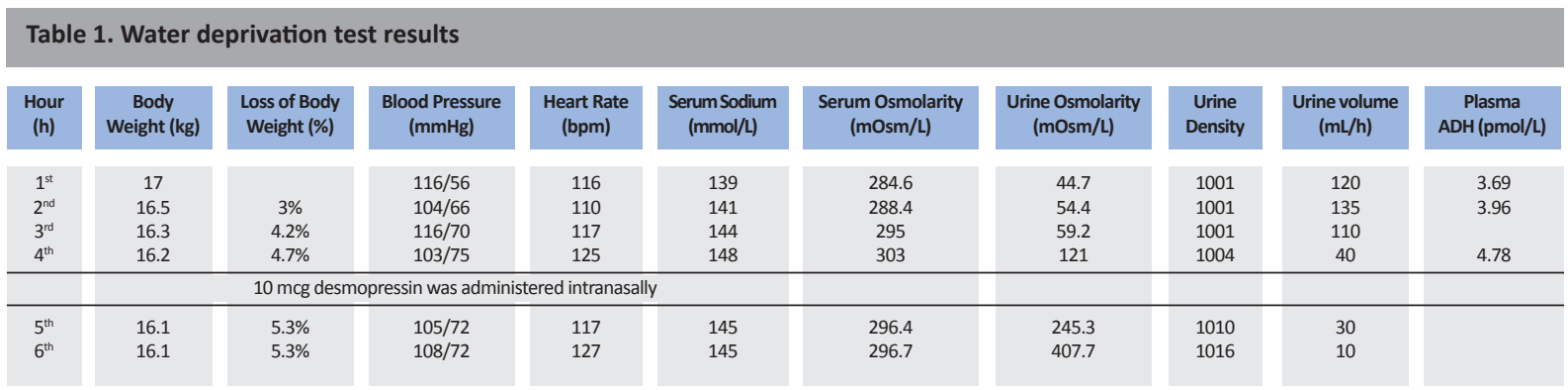




\begin{tabular}{|c|c|c|}
\hline Tests & Test Results & The Reference Range \\
\hline $\begin{array}{l}\text { TSH (mIU/L) } \\
\text { fT4 (pmol/L) } \\
\text { ACTH (ng/L) } \\
\text { Cortisol (nmol/L) }\end{array}$ & $\begin{array}{c}0.56 \\
13.5 \\
<5 \\
220.6\end{array}$ & $\begin{array}{c}(0.6-6.3) \\
(11.5-27) \\
(0-46) \\
(107.5-662)\end{array}$ \\
\hline & Cortisol repetition during stress is 772.4 & \\
\hline $\begin{array}{l}\text { IGF-1 }(\mu \mathrm{g} / \mathrm{L}) \\
\text { IGFBP-3 }(\mathrm{mg} / \mathrm{L}) \\
\text { Prolactin }(\mu \mathrm{g} / \mathrm{L})\end{array}$ & $\begin{array}{c}18.3(<-2 S D) \\
1.42(-2 /-1 S D) \\
22.06\end{array}$ & $\begin{array}{c}(50-286) \\
(1-4.7) \\
(2.5-17)\end{array}$ \\
\hline
\end{tabular}

and cortisol levels were observed. The patient's IGF-1 value was low. When the patient's clinical condition stabilized in the follow-up, it was planned to be examined for growth hormone deficiency. The patient with slightly lower thyroid-stimulating hormone with normal free thyroxine value was considered as euthyroid sick syndrome because of fever observed shortly after the test was performed. Follow-up of thyroid function tests was planned. Cortisol response of the patient during stress was within normal range.

In the follow-up of the patient, it was observed that his body temperature raised to $38-38.4^{\circ} \mathrm{C}$ in the evening once a day, and fell spontaneously and did not persist. On physical examination, any focus to explain the fever was not found. In laboratory tests, increases in acute phase reactants were observed (WBC: $14.89 \times 10^{9} / \mathrm{L}, \mathrm{PLT}: 722 \times 10^{9} / \mathrm{L}, \mathrm{C}$-reactive protein (CRP): $731.4 \mathrm{nmol} / \mathrm{L}(0-38)$, sedimentation rate: 70 $\mathrm{mm} / \mathrm{h}$ (0-10), ferritin: $81.3 \mu \mathrm{g} / \mathrm{L}$ (6-24), and fibrinogen: $3.96 \mathrm{~g} / \mathrm{L}(1.7-3.5))$. No pathogenic microorganism was isolated in the patient's blood or urine culture. Coagulation parameters, liver transaminases and kidney function tests of the patient were within normal limits.

Anemia was found in the laboratory tests performed during febrile episode ( $\mathrm{Hb}: 100 \mathrm{~g} / \mathrm{L}$, mean corpuscular volume (MCV): $66.5 \mathrm{fL}$ ) and the lungs were clear on chest $x$-ray. The patient with CDI and fever was consulted to the oncology department for the prediagnosis of LCH. A lytic expansile bone lesion in the mid-diaphyseal part of the left clavicle was found on

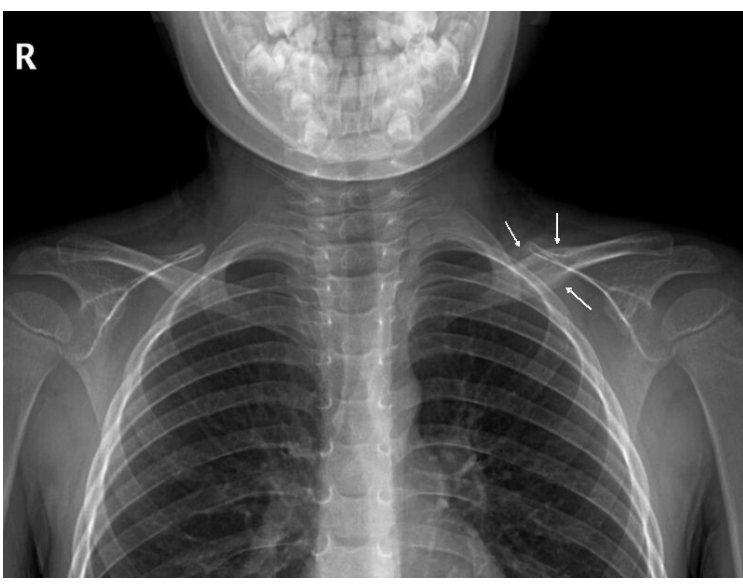

Figure 1. Skeletal survey of the patient shows a lytic expansile bone lesion in the mid- diaphyseal part of the left clavicle (white arrows)

skeletal survey (Figure 1). In the thorax computed tomography (CT) of the patient, a mass lesion with mild expansion, cortical thickening and cortical destruction was observed in the left clavicle middiaphyseal section. Lung parenchyma and other findings were unremarkable.

On magnetic resonance imaging (MRI) of the patient's pituitary gland, the height of the anterior pituitary gland was measured as $8 \mathrm{~mm}$ which was slightly increased according to the patient's age. The infundibulum was significantly thick and the transverse diameter was measured $6 \mathrm{~mm}$. The bright signal of the neurohypophysis was not observed in the T1-weighted image. In addition, heterogeneousnodular-mass-like enhancement was observed in the adenohypophysis and infundibulum after intravenous 


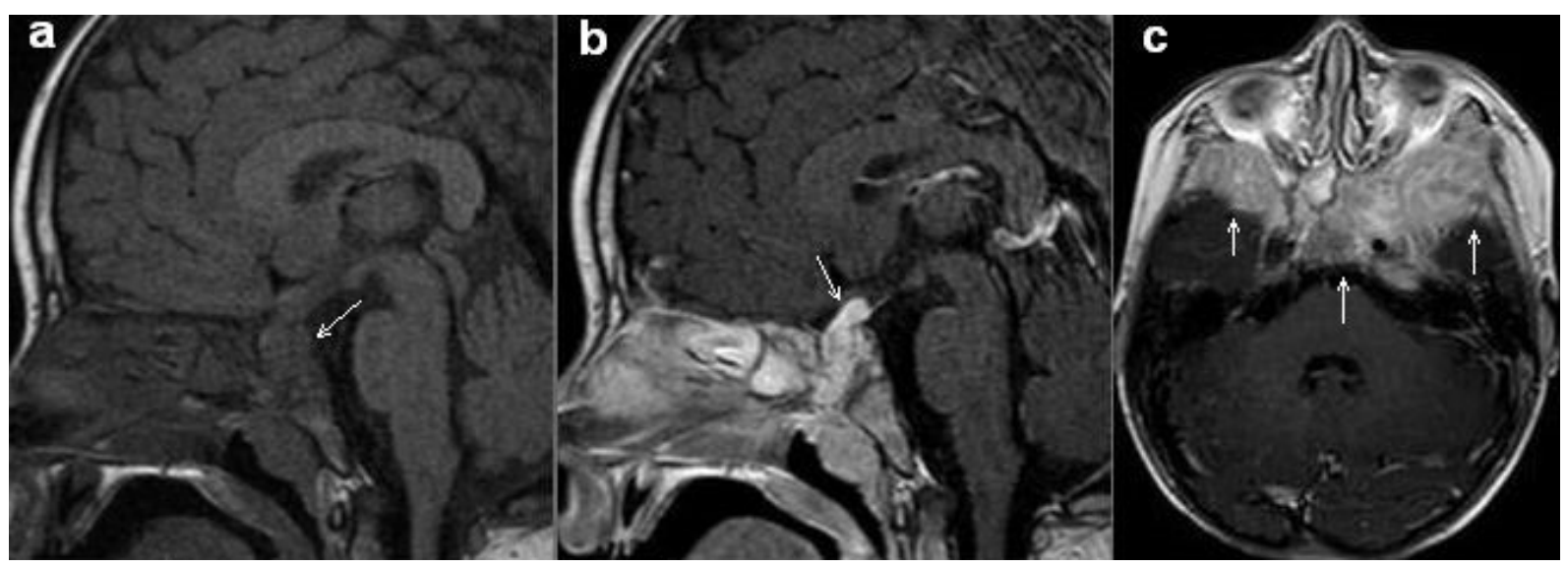

Figure 2 (a-c). Sagittal plane T1-weighted MR image (a) reveals the absence of posterior pituitary bright spot (white arrow). Note the destruction of sella turcica and the body of the sphenoid bone. Sagittal plane post-contrast T1-weighted MRI (b) demonstrates the thickened, and contrast-enhanced pituitary stalk (white arrow). Also, note the heterogeneous enhancement of the sphenoid bone around the pituitary gland. Axial plane post-contrast T1-weighted MRI of the brain (c) shows the destruction and infiltration of the skull base, more prominently on the sphenoid bone which is enhancing heterogeneously (white arrows)

contrast agent (IVCA) injection. On cranial MRI, widespread lytic-destructive bone lesions were observed in the bone structure forming the sella turcica, and the lateral wall of the left orbita. Also, intensely heterogeneous enhancement in the bone marrow was observed after IVCA injection (Figure 2). Because of the marked thickening in the infundibulum, serum alpha-fetoprotein and human chorionic gonadotropin levels of the patient were determined for the differential diagnosis of dysgerminoma. It was observed that the results were within normal ranges. The patient, who had a pre-diagnosis of $\mathrm{LCH}$, was directed to an external center for bone biopsy and it was learned that the treatment for the diagnosis of LCH was planned.

\section{DISCUSSION}

Central diabetes insipidus is a disease characterized by polyuria and polydipsia due to arginine vasopressin deficiency as a result of the destruction or degeneration of neurons originating from the supraoptic and paraventricular nuclei of the hypothalamus. Although $30-50 \%$ of the cases are idiopathic, known causes include intracranial tumors such as germinoma, craniopharyngioma, Langerhans' cell histiocytosis, granulomatous causes such as sarcoidosis, tuberculosis, hypoxic/ischemic vascular diseases, autoimmune diseases, trauma caused by central nervous system surgery or injury, and genetic defects that affect vasopressin synthesis. ${ }^{4}$ An organic cause should be investigated in children diagnosed with CDI. Various other diseases, especially germinomas, should be excluded. ${ }^{1}$ In a series of 34 children with $\mathrm{CDI}$, it was reported that four patients (7\%) had LHH in etiology. ${ }^{5}$ Central diabetes insipidus is the distinctive finding of HPA infiltration in cases with $\mathrm{LCH}$. It occurs in $25 \%$ of all patients with $\mathrm{LCH}$ or up to $50 \%$ of patients with multisystem disease. ${ }^{1}$ The frequency of isolated CDI has been reported to be less than 2 in 13 million per year in individuals younger than 18 years of age. ${ }^{6}$ In approximately $50 \%$ of cases with CDI, deficiency of anterior pituitary hormones also develops and causes growth retardation, hypothyroidism, hyperprolactinemia, hypoadrenalism, hypogonadism, amenorrhea, precocious puberty or delayed puberty. ${ }^{3}$

In our case, the presence of febrile episode that occurs once in the evening and falls off spontaneously led to the exclusion of infectious causes, but no pathological finding was found in the lung radiogram. Cases with $\mathrm{LCH}$ may sometimes present with fever and the importance of this finding is not clearly known. Tetsuko et al. analyzed $40 \mathrm{LCH}$ cases retrospectively in their study and reported that $25 \%$ had persistent fever at the beginning $\left(>38^{\circ} \mathrm{C}\right)$. They stated that cases with $\mathrm{LCH}$ who had fever at the time of diagnosis and had higher WBC, soluble interleukin-2 receptor and $\mathrm{CRP}$ values, lower $\mathrm{Hb}$ 
and MCV values indicated the presence of more intractable disease pattern. When the patterns of the febrile episodes of the patients were evaluated in the study, it was reported that periodic fever was observed in 2, persistent fever in 4, and intermittent fever in 2 patients. ${ }^{7}$ The fever of our case showed an intermittent course.

In the pituitary gland MRI of our case, it was observed that the height of the pituitary anterior gland was measured as $8 \mathrm{~mm}$ and increased slightly with age, the infundibulum was significantly thick and the transverse diameter was measured as 6 $\mathrm{mm}$, and the bright signal of the neurohypophysis was not observed in the T1-weighted image. Varan et al. evaluated pituitary imaging findings in 13 patients with Langerhans cell histiocytosis ( $\mathrm{LCH})$ and diabetes insipidus. The infundibulum was thickened in 11 (84.6\%), thread-like in 1 (7.7\%), and normal in 1 (7.7\%) patient. Posterior pituitary intensity was absent in 10 patients (76.9\%). In 4 patients, the pituitary gland was small in size, and 2 patients had atrophic pituitary. Three patients had a small sella. Infundibular thickening and absence of posterior pituitary intensity were the most common radiological findings. ${ }^{8}$

In the brain MRI findings of our case, diffuse lyticdestructive bone lesions were observed in the bony structure forming the sella, the sphenoid bone, and the left orbital lateral wall (Figure 2). Approximately $50 \%$ of cranial MRIs of patients with $\mathrm{LCH}$ have lesions in the craniofacial bones. ${ }^{1}$ In a study Lau et al. demonstrated that $50 \%$ of the cases with $\mathrm{LCH}$ had skull involvement which was significantly more frequently seen in cases with multiple system involvement compared to those with single system involvement (76\% versus $42 \%$ ). ${ }^{9}$ Lytic lesions of the skull bones are very common and these lesions may cause abrasions in the dura, but do not progress to the cortex. ${ }^{1}$

In our case, considering the diagnosis of $\mathrm{LCH}$ in presentation with isolated CDI, the presence of lowgrade fever with intermittent character emphasized that it is a warning sign for the diagnosis of LCH. But the patients with $\mathrm{CDI}$ should be evaluated in terms of $\mathrm{LHH}$, the most known underlying cause, regardless of the presence of fever.
Conflict of Interest: The authors declared no potential conflicts of interest with respect to the research, authorship, and/or publication of this article.

Funding: The authors received no financial support for the research, authorship, and/or publication of this article.

Informed Consent: Parents of the patient provided informed consent to publish the report.

\section{REFERENCES}

1. Grois N, Fahrner B, Arceci RJ, et al. Central nervous system disease in langerhans cell histiocytosis. J Pediatr. 2010;156:873-81. https://doi.org/10.1016/j.jpeds.2010.03.001

2. Guyot-Goubin A, Donadieu J, Barkaoui M, Bellec S, Thomas C, Clavel J. Descriptive epidemiology of childhood Langerhans cell histiocytosis in France, 2000-2004. Pediatr Blood Cancer 2008;51:71-5. https://doi.org/10.1002/pbc.21498

3. Leung AKC, Lam JM, Leong KF. Childhood Langerhans cell histiocytosis: a disease with many faces. World J Pediatr. 2019;15:536-45. https://doi.org/10.1007/s12519-019-00304-9

4. Maghnie M, Cosi G, Genovese E, et al. Central diabetes insipidus in children and young adults. N Engl J Med. 2000;343:998-1007. https://doi.org/10.1056/NEJM200010053431403

5. Catlı G, Abacı A, Korcan D, et al. Clinical profile and etiologies of children with central diabetes insipidus: a single-center experience from Turkey. J Pediatr Endocrinol Metab. 2012;25:499-502. https://doi.org/10.1515/jpem-2012-0006

6. Marchand I, Barkaoui MA, Garel C, Polak M, Donadieu J. Central diabetes insipidus as the inaugural manifestation of Langerhans cell histiocytosis: Natural history and medical evaluation of 26 children and adolescents. J Clin Endocrinol Metab. 2011;96:e1352-60. https://doi.org/10.1210/jc.2011-0513

7. Kobayashi T, Koga $Y$, Ishimura $M$, et al. Fever and skin involvement at diagnosis predicting the intractable Langerhans cell histiocytosis: 40 case-series in a single center. J Pediatr Hematol Oncol. 2018;40:e148-53. https://doi.org/10.1097/MPH.0000000000001080

8. Varan A, Cila A, Akyuz C, Kale G, Kutluk T, Buyukpamukcu M. Radiological evaluation of patients with pituitary langerhans cell histiocytosis at diagnosis and at followup. Pediatr Hematol Oncol. 2008;25:567-74. https://doi.org/10.1080/08880010802237112

9. Lau LMS, Stuurman K, Weitzman S. Skeletal Langerhans cell histiocytosis in children: Permanent consequences and health-related quality of life in long-term survivors. Pediatr Blood Cancer 2008;50:607-12. https://doi.org/10.1002/pbc.21322 